\title{
Childhood Estimates of Glomerular Filtration Rate Based on Creatinine and Cystatin C: Importance of Body Composition
}

\author{
Kozeta Miliku ${ }^{\mathrm{a}-c}$ Hanneke Bakker ${ }^{\mathrm{a}-c}$ Eiske M. Dorresteijn ${ }^{c}$ Karlien Cransberg ${ }^{c}$ \\ Oscar H. Franco ${ }^{\mathrm{b}}$ Janine F. Felix ${ }^{\mathrm{a}-\mathrm{c}}$ Vincent W.V. Jaddoe ${ }^{\mathrm{a}-\mathrm{c}}$ \\ ${ }^{a}$ The Generation R Study Group, ${ }^{b}$ Department of Epidemiology, and ${ }^{\mathrm{C}}$ Department of Pediatrics, \\ Erasmus MC, University Medical Center Rotterdam, Rotterdam, The Netherlands
}

\section{Keywords}

Estimate glomerular filtration rate $\cdot$ Creatinine .

Cystatin C · Body composition - Lean mass percentage .

Fat mass percentage $\cdot$ Pediatrics $\cdot$ Epidemiology

\begin{abstract}
Background: Creatinine and cystatin C concentrations are commonly used to estimate glomerular filtration rate (eGFR) in clinical practice and epidemiological studies. To estimate the influence of different body composition measures on eGFR from creatinine and cystatin C blood concentrations, we compared the associations of different anthropometric and body composition measures with eGFR derived from creatinine (eGFR creat) and cystatin C (eGFR cystc) blood concentrations. Methods: In a population-based cohort study among 4,305 children aged 6.0 years ( $95 \%$ range $5.7-8.0$ ), we measured weight and height and calculated body mass index (BMI) and body surface area (BSA), and lean and fat mass using dual-energy $\mathrm{X}$-ray absorptiometry. At the same age, we measured creatinine and cystatin $C$ blood concentrations and estimated the GFR. Results: Correlation between eGFR based on creatinine and cystatin $C$ concentrations was $r=$ 0.40 ( $p$ value $<0.01$ ). Higher BMI was associated with lower

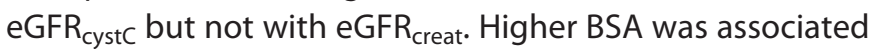
with higher eGFR $\mathrm{R}_{\text {creat }}$ and lower eGFR $\mathrm{Gystc}_{\text {c }}(p$ value $<0.05$ ). Lean and fat mass percentages were associated with eGFR $R_{\text {creat }}$

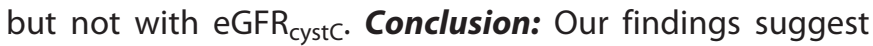

\section{KARGER}

E-Mail karger@karger.com www.karger.com/ajn
This article is licensed under the Creative Commons AttributionNonCommercial-NoDerivatives 4.0 International License (CC BY NC-ND) (http://www.karger.com/Services/OpenAccessLicense). Usage and distribution for commercial purposes as well as any distribution of modified material requires written permission. that both eGFR $R_{\text {creat }}$ and eGFR $\mathrm{R}_{\text {cystc }}$ are influenced by BMI and $B S A$. eGFR creat is more strongly influenced by body composition than eGFR $\mathrm{R}_{\text {cystc. }}$.

(C) 2017 The Author(s)

Published by S. Karger AG, Basel

\section{Introduction}

Glomerular filtration rate (GFR) plays a key role in the management of kidney disease. Ideally, measuring GFR should be based on renal clearances of exogenous markers such as inulin, but this approach is complex, invasive, and expensive [1]. Therefore, GFR is commonly estimated based on creatinine blood concentrations [2]. Using creatinine as marker of renal function has some limitations. Creatinine is actively secreted by the proximal tubule and related to muscle mass, age, sex, ethnicity, and dietary factors $[1,3]$. Creatinine concentrations can be higher in individuals with an increased muscle mass, independent of kidney function, leading to an underestimation of eGFR [4]. Studies in adults suggest that eGFR based on creatinine concentrations can be improved if lean mass percentage could be incorporated in the formula [4].

An alternative marker for the estimation of GFR is cystatin $\mathrm{C}$, the concentrations of which are reported to be independent of muscle mass in children $[5,6]$. Some authors report a superior sensitivity of cystatin $\mathrm{C}$ for detect-

Vincent W.V. Jaddoe, MD, PhD

The Generation R Study Group (Na-2915)

Erasmus MC, University Medical Center

PO Box 2040, NL-3000 CA Rotterdam (The Netherlands)

E-Mail v.jaddoe@erasmusmc.nl 
ing impaired GFR in pediatric patients to that of creatinine, especially in children with low muscle mass [7]. However, studies in kidney disease patients suggest that lean mass affects cystatin C concentrations [8, 9]. Many studies have explored the associations between body mass index (BMI) and eGFR, using BMI as a proxy for body composition $[10,11]$. To our knowledge, large population-based studies in healthy children comparing the correlations and associations of detailed body composition measures, next to BMI, with the estimates of GFR are lacking.

To estimate the influence of different body composition measures on eGFR from creatinine and cystatin C blood concentrations, we compared the associations of different anthropometric and body composition measures with eGFR derived from creatinine $\left(\mathrm{eGFR}_{\text {creat }}\right)$ and cystatin $\mathrm{C}\left(\mathrm{eGFR}_{\text {cystC }}\right)$ blood concentrations in a population-based prospective cohort study among 4,305 children who were 6 years of age.

\section{Methods}

\section{Design and Study Population}

This study was embedded in the Generation R Study, a population-based prospective cohort study from fetal life onward in Rotterdam, The Netherlands, which has been described in detail previously [12]. The study has been approved by Medical Ethical Committee of Erasmus MC, University Medical Center Rotterdam. All children were born between April 2002 and January 2006 and form a largely prenatally enrolled birth cohort that is currently being followed until young adulthood. Written consent was obtained for all children. The present analyses were performed among 4,305 children whose body composition details and kidney function measures available (online suppl. Fig. 1; for all online suppl. material, see www.karger.com/doi/10.1159/000463395).

\section{Body Composition Measurements}

Children's anthropometrics and body composition were measured at a median age of 6.0 years (95\% range 5.7-8.0) [12]. Height (m) was determined in standing position to the nearest millimeter without shoes using a Harpenden stadiometer (Holtain Limited, Dyfed, UK). Weight was measured using a mechanical personal scale (SECA, Almere, The Netherlands). We calculated BMI $\left(\mathrm{kg} / \mathrm{m}^{2}\right)$ and body surface area $\left(\mathrm{BSA} ; \mathrm{m}^{2}\right)$. For BSA, we used the DuBois formula: BSA $=$ weight $(\mathrm{kg})^{0.425} \times$ height $(\mathrm{cm})^{0.725} \times$ 0.007184 . Whole body dual-energy X-ray absorptiometry (DXA) scans (iDXA, GE-Lunar, 2008, Madison, WI, USA) were performed to estimate fat and lean mass. We calculated lean mass percentage as (lean mass [kg]/weight $[\mathrm{kg}]$ ) and fat mass percentage as (fat mass $[\mathrm{kg}] /$ weight $[\mathrm{kg}]$ ).

\section{Kidney Function Measurements}

Non-fasting blood samples were drawn by antecubital venipuncture and centrifuged for $10 \mathrm{~min}$ and stored at $-80^{\circ} \mathrm{C}$ at one location in the Stichting Trombosedienst and Artsenlaboratorium
Rijnmond (STAR)-MDC laboratory. As previously described, creatinine concentrations were measured with enzymatic methods and cystatin $\mathrm{C}$ concentrations with a particle enhanced immunoturbidimetric assay (using Cobas 8000 analyzers, Roche, Almere, The Netherlands). Quality control samples demonstrated intraand inter-assay coefficients of variation of $0.51 \%$ for creatinine and $1.65 \%$ for cystatin C, and $1.37 \%$ for creatinine and $1.13 \%$ for cystatin $\mathrm{C}$, respectively [13]. We calculated the eGFR based on creatinine concentrations according to the revised Schwartz 2009 formula: $\mathrm{eGFR}_{\text {creat }}=36.5 *$ (height $[\mathrm{cm}] /$ serum creatinine $\left.[\mu \mathrm{mol} / \mathrm{L}]\right)$ [14], and eGFR based on cystatin $C$ concentrations using Zappitelli's formula: $\mathrm{eGFR}_{\text {cystC }}=75.94 /\left(\mathrm{CysC}[\mathrm{mg} / \mathrm{L}]^{1.17}\right)[15]$.

\section{Statistical Analysis}

We performed a non-response analysis by comparing subject characteristics between children with and without kidney function measurements using $t$ tests, chi-square tests, and Mann-Whitney tests. We created SDs scores for all body composition measures to enable comparison between effect estimates. Next, we examined the Pearson rank correlation coefficients between childhood anthropometrics, body composition, and eGFR measures. Third, we used multiple linear regression analyses to examine the associations of anthropometric and body composition measures with creatinine, cystatin $\mathrm{C}$, eGFR $\mathrm{ereat}_{\text {, }}$ and $\mathrm{eGFR}_{\text {cystC. The linear regression }}$ models were adjusted for child sex, age at measurements, and ethnicity. Additionally, we explored the associations of childhood BMI clinical cutoffs with creatinine, cystatin C, and eGFRs. Because of the already reported associations of ethnicity with kidney function markers, we performed a sensitivity analysis in children of European ethnicity, the largest ethnic subgroup [16]. Based on previous literature, we assessed whether the explored association differed by sex, which was not the case in this study [17, 18]. All analyses were performed using the Statistical Package for the Social Sciences version 21.0 for Windows (SPSS IBM, Chicago, IL, USA).

\section{Results}

\section{Participant Characteristics}

Online supplementary Figure 1 describes the selection of the study population. At the median age of 6 years (95\% range 5.7-8.0) a total of 8,305 children participated in the study follow-up measurements. Of these children, 6,509 (78\%) visited the research center for body composition measurements. In this study, we excluded children with congenital kidney abnormalities $(n=12)$. A total of 6,497 children were available for kidney function measurements. Of these children, 2,192 children did not have kidney measurements. The present analyses were performed among 4,305 children whose body composition and kidney function measures available.

Table 1 shows the characteristics of the participants. In the full group, the mean (SD) eGFR $\mathrm{ereat}_{\text {and }} \mathrm{GFF}_{\text {cystc }}$ were $118.9 \mathrm{~mL} / \mathrm{min} / 1.73 \mathrm{~m}^{2}$ (15.9) and $101.6 \mathrm{~mL} / \mathrm{min} / 1.73 \mathrm{~m}^{2}$ (11.2), respectively. The histograms of creatinine, cystatin

Am J Nephrol 2017;45:320-326

DOI: $10.1159 / 000463395$

Body Composition and GFR Estimates

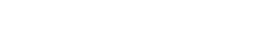




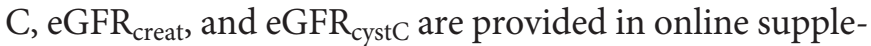
mentary Figure 2. Results from the non-response analyses are given in the online supplementary Table 1. Children with kidney function measurements had higher lean mass percentage and lower fat mass percentage compared to children who did not have kidney function measurements.

\section{Correlations of Childhood Anthropometrics and Body} Composition Measures with eGFR

The Pearson rank correlation coefficient between $\mathrm{eGFR}_{\text {creat }}$ and $\mathrm{eGFR}_{\text {cystC }}$ was $r=0.40$ ( $p$ value $<0.01$; Table 2). Childhood height, weight, BMI, and BSA were positively correlated with creatinine and cystatin $\mathrm{C}$ concentrations, with stronger coefficients for creatinine concentrations ( $p$ value $<0.01$ ). Lean mass percentage was positively correlated with creatinine concentrations and negatively correlated with eGFR creat $(r=0.13, p$ value $<0.01)$. Similar results, but in opposite directions, were observed for fat mass percentage. Lean mass percentage and fat mass percentage were not correlated with cystatin $\mathrm{C}$ concentrations or eGFR $\mathrm{Fyst}_{\text {c }}$.

\section{Associations of Childhood Body Composition \\ Measures with eGFR}

Table 3 shows the results from the linear regression models. Childhood height was associated with creatinine concentrations ( $p$ value $<0.05$ ), but not with cystatin C concentrations. Higher childhood weight was associated with both higher creatinine and cystatin $\mathrm{C}$ concentrations ( $p$ value $<0.01$ ). Higher childhood height was associated with highereGFR creat $(p$ value $<0.01)$, but not with eGFR cystC whereas higher childhood weight was associated with higher eGFR creat $_{\text {and lower eGFR }}$ cystC $(p$ value $<0.01)$.

Each 1-SD increase in BSA was associated with 1.81 $\mathrm{mL} / \mathrm{min} / 1.73 \mathrm{~m}^{2}$ (95\% CI 1.24-2.37) higher eGFR creat $_{\text {and }}$ $0.57 \mathrm{~mL} / \mathrm{min} / 1.73 \mathrm{~m}^{2}$ (95\% CI -0.98 to -0.17 ) lower eGFR cystC. BMI was negatively associated with eGFR $_{\text {cystC }}$ ( $p$ value $<0.05$ ) but not with eGFR creat . We observed tendencies for similar effect estimates when we restricted the analyses to Europeans only ( $n=2,727$; online suppl. Table 2). The associations of BMI clinical cutoffs with creatinine, cystatin $\mathrm{C}$, and the eGFR are given in online supplementary Table 3.

Higher lean mass percentage was associated with higher creatinine concentrations and with lower cystatin C concentrations (Table 3; $p$ value $<0.05$ ). A 1-SD increase in lean mass percentage was associated with $2.74 \mathrm{~mL} / \mathrm{min} / 1.73 \mathrm{~m}^{2}$

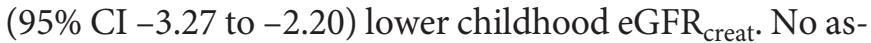
sociation was observed of lean mass percentage with eGFR $_{\text {cystC }}$.
Table 1. Subjects characteristics $(n=4,305)$

\begin{tabular}{|c|c|}
\hline Age at measurements, years & $6.0(5.7-8.0)$ \\
\hline Gender, female, $\%$ & 48.3 \\
\hline \multicolumn{2}{|l|}{ Ethnicity, \% } \\
\hline Dutch or European & 65.1 \\
\hline Non-European & 34.9 \\
\hline Height, m & $119.7(6.0)$ \\
\hline SD score*, mean (SD) & $-0.2(1.0)$ \\
\hline Weight, kg & $23.4(4.2)$ \\
\hline SD score*, mean (SD) & $0.1(1.0)$ \\
\hline Body mass index, $\mathrm{kg} / \mathrm{m}^{2}$ & $16.2(1.8)$ \\
\hline SD score*, mean $(\mathrm{SD})$ & $0.3(0.9)$ \\
\hline Body surface area, $\mathrm{m}^{2}$ & $0.88(0.09)$ \\
\hline Fat mass percentage, $\%$ & $24.7(5.6)$ \\
\hline Lean mass percentage, $\%$ & $71.7(5.4)$ \\
\hline $\mathrm{eGFR}_{\text {creat }}, \mathrm{mL} / \mathrm{min} / 1.73 \mathrm{~m}^{2}$ & $118.9(15.9)$ \\
\hline $\mathrm{eGFR}_{\text {cystC }}, \mathrm{mL} / \mathrm{min} / 1.73 \mathrm{~m}^{2}$ & $101.6(11.2)$ \\
\hline
\end{tabular}

Values are percentages for categorical variables, means (SD) for continuous variables with a normal distribution, or medians (95\% range) for continuous variables with a skewed distribution. * The SD scores were obtained using Dutch reference growth curves (Growth Analyzer 3.0, Dutch Growth Research Foundation, Rotterdam, The Netherlands). $\mathrm{eGFR}_{\text {creat }}$, estimated glomerular filtration rate calculated based on creatinine blood concentrations; $\mathrm{eGFR}_{\text {creat }}=36.5^{*}$ (height $[\mathrm{cm}] /$ serum creatinine $[\mu \mathrm{mol} / \mathrm{L}]) ; \mathrm{eGFR}_{\mathrm{cystC}}$, estimated glomerular filtration rate calculated based on cystatin C blood concentrations; $\mathrm{eGFR}_{\text {cystC }}=75.94 /(\mathrm{cysC}$ $\left.[\mathrm{mg} / \mathrm{L}]^{1.17}\right)$.

Similar results, but in an opposite direction, were observed for fat mass percentage (Table 3). We observed similar effect estimates when we restricted our analyses to European subjects only, although not all associations were significant (online suppl. Table 2).

\section{Discussion}

Results of this cross-sectional study in healthy 6-yearold children suggest that BMI and BSA are associated with creatinine-based and cystatin C-based eGFRs. Lean mass percentage and fat mass percentage are associated with creatinine-based eGFR, but not with cystatin C-based eGFR.

\section{Interpretation of Main Findings}

To our knowledge, this is the first large populationbased study in healthy school-age children comparing the association of detailed measures of body composition using DXA scans with estimates of GFR based on creatinine and cystatin $\mathrm{C}$ concentrations. Both creatinine and cystatin $\mathrm{C}$ concentrations can be influenced by different factors. Creatinine is produced in active muscle and is re- 
Table 2. Correlation coefficients of the investigated variables

\begin{tabular}{|c|c|c|c|c|c|c|c|c|c|c|}
\hline & Height & Weight & BMI & BSA & FMP & LMP & Creat & Cyst C & $\mathrm{eGFR}_{\text {creat }}$ & $\mathrm{eGFR}_{\text {cystC }}$ \\
\hline Height & 1.00 & & & & & & & & & \\
\hline Weight & $0.77^{*}$ & 1.00 & & & & & & & & \\
\hline BMI & $0.31^{*}$ & $0.83^{*}$ & 1.00 & & & & & & & \\
\hline BSA & $0.90^{*}$ & $0.97^{*}$ & $0.69^{*}$ & 1.00 & & & & & & \\
\hline FMP & $0.18^{*}$ & $0.57^{*}$ & $0.69^{*}$ & $0.46^{*}$ & 1.00 & & & & & \\
\hline LMP & $-0.19^{*}$ & $-0.56^{*}$ & $-0.68 *$ & $-0.45^{*}$ & $-0.999 *$ & 1.00 & & & & \\
\hline Creat & $0.30^{*}$ & $0.28^{*}$ & $0.16^{*}$ & $0.30^{*}$ & $-0.05^{*}$ & $0.05^{*}$ & 1.00 & & & \\
\hline Cyst C & $0.05^{*}$ & $0.06^{*}$ & $0.05^{*}$ & $0.06^{*}$ & -0.001 & 0.003 & $0.40^{*}$ & 1.00 & & \\
\hline eGFR ${ }_{\text {creat }}$ & $0.06^{*}$ & 0.01 & $-0.04^{*}$ & 0.03 & $0.12 *$ & $-0.13^{*}$ & $-0.92^{*}$ & $-0.40^{*}$ & 1.00 & \\
\hline $\mathrm{eGFR}_{\text {cystC }}$ & $-0.05^{*}$ & $-0.06^{*}$ & $-0.05^{*}$ & $-0.06^{*}$ & 0.01 & -0.01 & $-0.39^{*}$ & $-0.99 *$ & $0.40^{*}$ & 1.00 \\
\hline
\end{tabular}

* Correlation is significant at the 0.01 level (2-tailed).

BMI, body mass index; BSA, body surface area; FMP, fat mass percentage; LMP, lean mass percentage; creat, creatinine; Cyst C,

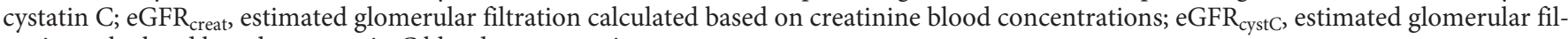
tration calculated based on cystatin C blood concentrations.

Table 3. Associations of anthropometric and body composition measures with creatinine, cystatin C, and eGFR $(n=4,305)$

\begin{tabular}{|c|c|c|c|c|}
\hline \multirow{2}{*}{$\begin{array}{l}\text { Anthropometrics and } \\
\text { body composition (SDS) }\end{array}$} & \multicolumn{4}{|c|}{ Difference $(95 \% \mathrm{CI})$} \\
\hline & $\begin{array}{l}\text { creatinine, } \\
\mu \mathrm{mol} / \mathrm{L}\end{array}$ & $\begin{array}{l}\text { cystatin } \mathrm{C}, \\
\mu \mathrm{g} / \mathrm{L}\end{array}$ & $\begin{array}{l}\text { eGFRcreat, } \\
\mathrm{mL} / \mathrm{min} / 1.73 \mathrm{~m}^{2}\end{array}$ & $\begin{array}{l}\text { eGFRcystC, } \\
\mathrm{mL} / \mathrm{min} / 1.73 \mathrm{~m}^{2}\end{array}$ \\
\hline Height & $0.97(0.79 \text { to } 1.15)^{* * *}$ & $1.99(-0.70$ to 4.70$)$ & $2.78(2.22 \text { to } 3.35)^{* * *}$ & $-0.29(-0.70$ to 0.12$)$ \\
\hline Weight & $0.91(0.73 \text { to } 1.08)^{* * *}$ & $4.49(1.91 \text { to } 7.07)^{* * *}$ & $1.16(0.61 \text { to } 1.71)^{* * *}$ & $-0.66(-1.05 \text { to }-0.27)^{* *}$ \\
\hline Body mass index & $0.52(0.36 \text { to } 0.68)^{* * *}$ & $4.15(1.80 \text { to } 6.51)^{* * *}$ & $-0.37(-0.87$ to 0.13$)$ & $-0.61(-0.96 \text { to }-0.26)^{* *}$ \\
\hline Body surface area & $1.02(0.84 \text { to } 1.20)^{* * *}$ & $3.93(1.27 \text { to } 6.59)^{* *}$ & $1.81(1.24 \text { to } 2.37)^{* * *}$ & $-0.57(-0.98 \text { to }-0.17)^{* *}$ \\
\hline Lean mass percentage & $0.30(0.07 \text { to } 0.54)^{*}$ & $-2.73(-5.28 \text { to }-0.18)^{*}$ & $-2.74(-3.27 \text { to }-2.20)^{* * *}$ & $0.36(-0.03$ to 0.74$)$ \\
\hline Fat mass percentage & $-0.48(-0.65 \text { to }-0.31)^{* * *}$ & $2.86(0.32 \text { to } 5.40)^{*}$ & $2.68(2.14 \text { to } 3.21)^{* * *}$ & $-0.38(-0.76$ to 0.01$)$ \\
\hline
\end{tabular}

Values are beta coefficients and 95\% CIs, from linear regression models adjusted for child age, sex, and ethnicity. eGFR creat $_{\text {, }}$ estimated glomerular filtration rate calculated based on creatinine blood concentrations; $\mathrm{EGFR}_{\mathrm{cystC}}$, estimated glomerular filtration rate calculated based on cystatin $\mathrm{C}$ blood concentrations.

$p$ value for the associations $* p<0.05,{ }^{* *} p<0.01$, and ${ }^{* * *} p<0.001$.

ported to be determined by muscle mass and dietary intake, which may account for the variations in the concentrations of serum creatinine observed among different age and ethnic groups $[1,3]$. However, we have previously reported that childhood protein intake does not influence the eGFR [19]. Cystatin C is another marker to evaluate renal function, although it is not used as commonly as creatinine $[6,20]$. Cystatin $C$ is produced by all nucleated cells and reported to be less strongly related to body weight and height in children compared to creatinine $[5,7]$. Besides, adult studies suggest that cystatin $\mathrm{C}$ concentrations are related to age, sex, height, and weight and influenced by corticosteroid use [17, 21].

In children, the Schwartz formula is widely used to estimate GFR from creatinine concentrations [14]. The
Schwartz formula is known to overestimate eGFR compared to inulin clearance GFR $[6,22,23]$. Schwartz formula estimates GFR using creatinine concentrations and child height [14]. Therefore, the observed effect estimates

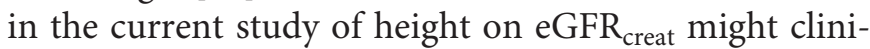
cally not be relevant. Next to Schwartz's formula, we estimated GFR using the Zappitelli's formula [15]. This formula is not dependent of any anthropometric measures. It estimates GFR by using only the cystatin C concentrations [15]. In a study among 42 healthy adults, eGFR using creatinine and cystatin $\mathrm{C}$ concentrations were compared with measured GFR. This study suggested that eGFR based on cystatin $\mathrm{C}$ concentrations was a better marker then eGFR based on creatinine concentrations for estimating kidney function [24]. 
It has previously been reported that lean body mass, indicating muscular mass, is an important determinant of the GFR [25]. So far, results from studies comparing the effects of body composition measures on creatinine and cystatin $\mathrm{C}$ concentrations and their derived eGFR are contradictory $[8,26]$. A number of studies have explored the associations of BMI with eGFR, using BMI as a proxy of body composition $[10,11]$. The associations of BMI with creatinine and cystatin $\mathrm{C}$ differed between populations studied. We observed that higher BMI was associated with higher creatinine and cystatin $C$ concentrations and with lower eGFR $\mathrm{GystC}_{\text {, }}$ but not with

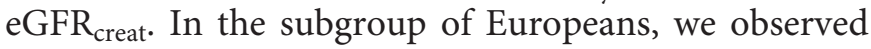
that BMI was associated with creatinine, cystatin C concentrations, and their derived eGFRs. In line with our findings in the European subgroup, in the general Japanese population, BMI was associated with lower $\mathrm{eGFR}_{\text {creat }}[11]$. Similar to what we observe, studies among both healthy and kidney disease adults suggested that eGFR based on cystatin C concentrations is not independent of BMI $[8,27]$. These findings appear to be different among children with various kidney diseases, where BMI does not have a clinically relevant effect on eGFR $\mathrm{CystC}_{\mathrm{c}}$ [10]. Next to BMI, we observed that higher BSA was associated with higher creatinine, cystatin $\mathrm{C}$ concentrations, eGFR creat $_{\text {, and lower eGFR }}$ cystc. The effect estimates for the associations of BMI and BSA with eGFRs are relatively small. Studying detailed measures of body composition will therefore likely add to the understanding of the associations of body composition and kidney function measures.

Studies among healthy adults have shown lean mass percentage to be associated with serum creatinine and eGFR based on creatinine concentrations but not with cystatin C concentrations $[4,26]$. A study among 67 healthy individuals of ages between 18 and 52 years has shown that creatinine concentrations were highly affected by muscle mass, whereas cystatin $\mathrm{C}$ concentrations were affected by fat mass [28]. The associations between lean mass and cystatin $\mathrm{C}$ are reported to be different among kidney disease patients [8]. Among 77 chronic kidney disease patients lean mass affected cystatin C concentrations, and GFR estimation based on cystatin C concentrations improved when lean mass was included in the formula, especially in patients with extreme body composition [8]. In severely obese children, lean mass percentage has been reported to correlate with both creatinine and cystatin C concentrations [29]. In the current study, we observed that lean and fat mass percentage correlate with creatinine concentrations and eGFR creat. Higher lean mass percentage and lower fat mass percentage were associated with higher creatinine concentrations and lower $\mathrm{eGFR}_{\text {creat }}$. We did not observe a significant correlation of lean mass percentage or fat mass percentage with cystatin C concentrations. Our study shows that eGFR based on cystatin $\mathrm{C}$ concentrations is independent of lean mass percentage and fat mass percentage.

Our findings suggest that $\mathrm{eGFR}_{\text {creat }}$ is more strongly influenced by body composition than eGFR $\mathrm{cystC}_{\text {. How- }}$ ever, their impact on clinical care may be limited. As the revised Schwartz formula $\left(\mathrm{eGFR}_{\text {creat }}\right)$ is the most widely used formula both in epidemiological studies and clinical practice, our findings suggest that body composition measures should be considered when eGFR is based on creatinine concentrations. Ideally, body composition measures would have been incorpo-

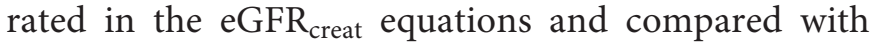
GFR based on renal clearances of exogenous markers, but unfortunately this is not possible in our study. Considering the feasibility and costs of performing DXA scans in school-age children, whether and to what extent detailed body composition measures should be used in the clinical practice when estimating GFR can be argued. Other studies are needed to assess whether using eGFR cystC instead of eGFR creat $_{\text {ceads to }}$ better care for pediatric kidney patients.

\section{Strengths and Limitations}

To the best of our knowledge, this is the first and largest cross-sectional multiethnic study in a healthy pediatric population-based cohort examining the associations of body composition with estimates of GFR. GFR was estimated based on creatinine and cystatin C concentrations. Except height and weight to calculate BMI and BSA, we also measured fat mass and lean mass with DXA. Of all children, $61 \%$ provided blood samples for measuring creatinine and cystatin $\mathrm{C}$ concentrations. Children without data on kidney function measures were shorter, had a higher fat mass percentage, and lower lean mass percentage. The difference in fat and lean mass percentage may be explained by the higher percentage of girls in the group without available kidney measures. There was no difference in BMI between the children with and without available kidney function measures. We observed tendencies for similar effect estimates among Europeans only, although not all associations were significant in this subgroup. This might be due to the smaller study group, but may also reflect an effect of ethnicity. Ideally, we would have been able to compare the explored associations with the measured GFR and validate our findings. 
Unfortunately, we do not have the urinary or plasma clearance of an ideal filtration marker, such as inulin, iothalamate, or iohexol, as the gold standard for the measurement of GFR [30]. Our findings are based on a healthy pediatric population of a narrow age category and may not be generalizable to older, younger, or diseased populations.

\section{Conclusion}

Our results suggest that eGFR based on both creatinine and cystatin $\mathrm{C}$ concentrations are influenced by BMI and BSA, whereas only eGFR based on creatinine concentrations is influenced by lean mass percentage and fat mass percentage. Beside anthropometric measurements, body composition measures should be considered when estimating GFR in children. Further studies to compare these results with measured GFR are needed.

\section{Acknowledgments}

The Generation R Study is conducted by the Erasmus MC, University Medical Center in close collaboration with the School of Law and Faculty of Social Sciences of the Erasmus University Rotterdam, the Municipal Health Service Rotterdam area, Rotterdam, the Rotterdam Homecare Foundation, Rotterdam and the STAR, Rotterdam. We gratefully acknowledge the contribution of participating mothers, general practitioners, hospitals, midwives, and pharmacies in Rotterdam.

\section{Author Contributions}

K.M. and V.W.V.J. designed the research and wrote the paper. K.M. analyzed the data. H.B., E.M.D., K.C., O.H.F., and J.F.F. provided comments and consultation regarding the analyses, interpretation of the results, and manuscript. K.M. had primary responsibility for final content. All authors gave final approval of the version to be published.

\section{Financial Support}

The general design of Generation R Study is made possible by financial support from the Erasmus MC, University Medical Center, Rotterdam, The Netherlands Organization for Health Research and Development (ZonMw), The Netherlands Organisation for Scientific Research (NWO), the Ministry of Health, Welfare and Sport and the Ministry of Youth and Families. K.M. has been financially supported through Erasmus Mundus Western Balkans, a project funded by the European Commission. O.H.F. works in ErasmusAGE, a center for aging research across the life course funded by Nestlé Nutrition (Nestec Ltd.); Metagenics Inc.; and AXA. J.F.F. has received funding from the European Union's Horizon 2020 research and innovation program under grant agreement No. 633595 (DynaHEALTH). V.W.V.J. received an additional grant from The Netherlands Organization for Health Research and Development (VIDI 016.136.361) and a European Research Council Consolidator Grant (ERC-2014-CoG-648916). The funders had no role in design and conduct of the study; collection, management, analysis, and interpretation of the data; and preparation, review, or approval of the manuscript.

\section{Disclosure Statement}

The authors declare no conflict of interest.

\section{References}

1 Stevens LA, Coresh J, Greene T, Levey AS: Assessing kidney function - measured and estimated glomerular filtration rate. $\mathrm{N}$ Engl $\mathrm{J}$ Med 2006;354:2473-2483.

2 National Kidney Foundation: K/DOQI clinical practice guidelines for chronic kidney disease: evaluation, classification, and stratification. Am J Kidney Dis 2002;39(2 suppl 1):S1-S266.

- 3 Jones CA, McQuillan GM, Kusek JW, Eberhardt MS, Herman WH, Coresh J, Salive M, Jones CP, Agodoa LY: Serum creatinine levels in the US population: third national health and nutrition examination survey. Am J Kidney Dis 1998;32:992-999.

-4 Gunnarsson SI, Palsson R, Sigurdsson G, Indridason OS: Relationship between body composition and glomerular filtration rate estimates in the general population. Nephron Clin Pract 2013;123:22-27.

5 Filler G, Bokenkamp A, Hofmann W, Le Bricon T, Martinez-Bru C, Grubb A: Cystatin C as a marker of GFR - history, indications, and future research. Clin Biochem 2005;38: $1-8$.

6 Bacchetta J, Cochat P, Rognant N, Ranchin B, Hadj-Aissa A, Dubourg L: Which creatinine and cystatin $\mathrm{C}$ equations can be reliably used in children? Clin J Am Soc Nephrol 2011;6: 552-560.

-7 Andersen TB, Eskild-Jensen A, Frokiaer J, Brochner-Mortensen J: Measuring glomerular filtration rate in children; can cystatin C replace established methods? A review. Pediatr Nephrol 2009;24:929-941.

8 Macdonald J, Marcora S, Jibani M, Roberts G, Kumwenda M, Glover R, Barron J, Lemmey A: GFR estimation using cystatin $C$ is not independent of body composition. Am J Kidney Dis 2006;48:712-719.

-9 Stevens LA, Schmid CH, Greene T, Li L, Beck GJ, Joffe MM, Froissart M, Kusek JW, Zhang YL, Coresh J, Levey AS: Factors other than glomerular filtration rate affect serum cystatin C levels. Kidney Int 2009;75:652660.

10 Sharma AP, Kathiravelu A, Nadarajah R, Ya$\sin$ A, Filler G: Body mass does not have a clinically relevant effect on cystatin C eGFR in children. Nephrol Dial Transplant 2009;24: 470-474.

11 Kawamoto R, Kohara K, Tabara Y, Miki T, Ohtsuka N, Kusunoki T, Yorimitsu N: An association between body mass index and estimated glomerular filtration rate. Hypertens Res 2008;31:1559-1564.

12 Jaddoe VW, van Duijn CM, Franco OH, van der Heijden AJ, van Iizendoorn MH, de Jongste JC, van der Lugt A, Mackenbach JP, Moll HA, Raat H, Rivadeneira F, Steegers EA, Tiemeier H, Uitterlinden AG, Verhulst FC, Hofman A: The Generation R Study: design and cohort update 2012. Eur J Epidemiol 2012;27: 739-756.

Body Composition and GFR Estimates 
13 Miliku K, Voortman T, Bakker H, Hofman A, Franco OH, Jaddoe VW: Infant breastfeeding and kidney function in school-aged children. Am J Kidney Dis 2015;66:421-428.

14 Schwartz GJ, Munoz A, Schneider MF, Mak RH, Kaskel F, Warady BA, Furth SL: New equations to estimate GFR in children with CKD. J Am Soc Nephrol 2009;20:629-637.

$\checkmark 15$ Zappitelli M, Parvex P, Joseph L, Paradis G, Grey V, Lau S, Bell L: Derivation and validation of cystatin C-based prediction equations for GFR in children. Am J Kidney Dis 2006; 48:221-230.

-16 Bakker H, Kooijman MN, van der Heijden AJ, Hofman A, Franco OH, Taal HR, Jaddoe VW: Kidney size and function in a multi-ethnic population-based cohort of school-age children. Pediatr Nephrol 2014;29:15891598.

17 Groesbeck D, Kottgen A, Parekh R, Selvin E, Schwartz GJ, Coresh J, Furth S: Age, gender, and race effects on cystatin C levels in US adolescents. Clin J Am Soc Nephrol 2008;3: 1777-1785.

18 Bokenkamp A, Domanetzki M, Zinck R, Schumann G, Byrd D, Brodehl J: Cystatin C - a new marker of glomerular filtration rate in children independent of age and height. Pediatrics $1998 ; 101: 875-881$.
19 Voortman T, Bakker H, Sedaghat S, Kiefte-de Jong JC, Hofman A, Jaddoe VW, Franco OH, van den Hooven EH: Protein intake in infancy and kidney size and function at the age of 6 years: the Generation R Study. Pediatr Nephrol 2015;30:1825-1833.

-20 Bokenkamp A, Herget-Rosenthal S, Bokenkamp R: Cystatin C, kidney function and cardiovascular disease. Pediatr Nephrol 2006;21: 1223-1230.

-21 Knight EL, Verhave JC, Spiegelman D, Hillege HL, de Zeeuw D, Curhan GC, de Jong PE: Factors influencing serum cystatin $C$ levels other than renal function and the impact on renal function measurement. Kidney Int 2004;65:1416-1421.

22 van Rossum LK, Mathot RA, Cransberg K, Zietse R, Vulto AG: Estimation of the glomerular filtration rate in children: which algorithm should be used? Pediatr Nephrol 2005;20: 1769-1775.

23 Vroling AB, Dorresteijn EM, Cransberg K, de Rijke YB: The impact of estimated glomerular filtration rate equations on chronic kidney disease staging in pediatric renal or heart transplant recipients. Pediatr Nephrol 2016; 31:1145-1155.

24 Vinge E, Lindergard B, Nilsson-Ehle P, Grubb A: Relationships among serum cystatin C, serum creatinine, lean tissue mass and glomerular filtration rate in healthy adults. Scand J Clin Lab Invest 1999;59:587-592.
25 Chew-Harris JS, Florkowski CM, Elmslie JL, Livesey J, Endre ZH, George PM: Lean mass modulates glomerular filtration rate in males of normal and extreme body composition. Intern Med J 2014;44:749-756.

26 Baxmann AC, Ahmed MS, Marques NC, Menon VB, Pereira AB, Kirsztajn GM, Heilberg IP: Influence of muscle mass and physical activity on serum and urinary creatinine and serum cystatin C. Clin J Am Soc Nephrol 2008; 3:348-354.

27 Galteau MM, Guyon M, Gueguen R, Siest G: Determination of serum cystatin C: biological variation and reference values. Clin Chem Lab Med 2001;39:850-857.

28 Chew-Harris JS, Florkowski CM, George PM, Elmslie JL, Endre ZH: The relative effects of fat versus muscle mass on cystatin $\mathrm{C}$ and estimates of renal function in healthy young men. Ann Clin Biochem 2013;50(pt 1):39-46.

29 Codoner-Franch P, Ballester-Asensio E, Martinez-Pons L, Vallecillo-Hernandez J, Navarro-Ruiz A, del Valle-Perez R: Cystatin $\mathrm{C}$, cardiometabolic risk, and body composition in severely obese children. Pediatr Nephrol 2011;26:301-307.

30 Stevens LA, Levey AS: Measured GFR as a confirmatory test for estimated GFR. J Am Soc Nephrol 2009;20:2305-2313. 